
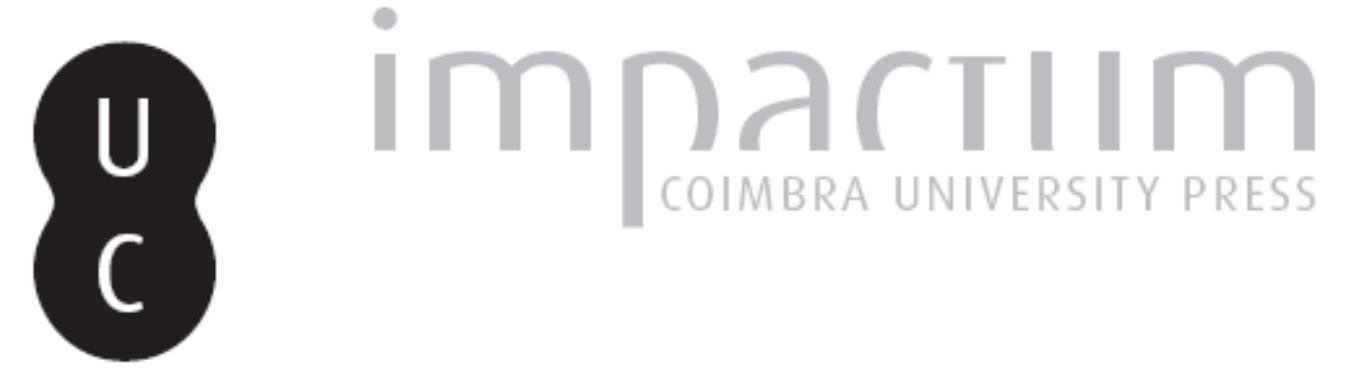

\title{
Avaliação e controlo de riscos químicos graves e a protecção civil, no transporte e na directiva "SEVESO II"
}

\author{
Autor(es): $\quad$ Mondril, Nuno Camacho
}

Publicado por: Associação Portuguesa de Riscos, Prevenção e Segurança

URL persistente:

URl:http://hdl.handle.net/10316.2/36084

DOI:

DOI:http://dx.doi.org/10.14195/1647-7723_18_28

Accessed : $\quad$ 26-Apr-2023 13:30:57

A navegação consulta e descarregamento dos títulos inseridos nas Bibliotecas Digitais UC Digitalis, UC Pombalina e UC Impactum, pressupõem a aceitação plena e sem reservas dos Termos e Condições de Uso destas Bibliotecas Digitais, disponíveis em https://digitalis.uc.pt/pt-pt/termos.

Conforme exposto nos referidos Termos e Condições de Uso, o descarregamento de títulos de acesso restrito requer uma licença válida de autorização devendo o utilizador aceder ao(s) documento(s) a partir de um endereço de IP da instituição detentora da supramencionada licença.

Ao utilizador é apenas permitido o descarregamento para uso pessoal, pelo que o emprego do(s) título(s) descarregado(s) para outro fim, designadamente comercial, carece de autorização do respetivo autor ou editor da obra.

Na medida em que todas as obras da UC Digitalis se encontram protegidas pelo Código do Direito de Autor e Direitos Conexos e demais legislação aplicável, toda a cópia, parcial ou total, deste documento, nos casos em que é legalmente admitida, deverá conter ou fazer-se acompanhar por este aviso.

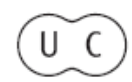




\section{territorium}

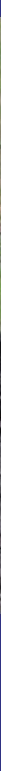

\section{Afirmar as Ciências Cindínicas}

Revista da Associação Portuguesa de Riscos, Prevenção e Segurança 
territorium 18

\section{AVALIAÇÃO E CONTROLO DE RISCOS QUÍMICOS GRAVES E A PROTECÇÃO CIVIL, NO TRANSPORTE E NA DIRECTIVA “SEVESO II".*}

Nuno Camacho Mondril

Autoridade Nacional de Protecção Civil nuno.mondril@prociv.pt

\section{RESUMO}

Esta comunicação expõe as formas de actuação da Autoridade Nacional de Protecção Civil (ANPC) e das entidades públicas e privadas, no contexto do sistema de protecção civil, face aos riscos colectivos decorrentes do transporte de matérias perigosas e das instalações fixas com produtos químicos (abrangidos pela Directiva "SEVESO II" 96/82/CE), na gestão das emergências e das catástrofes e na avaliação e cartografia dos riscos químicos graves, na sua prevenção, preparação, planeamento e adequação dos instrumentos de gestão do território.

Palavras chave: Riscos químicos graves; Directiva "SEVESO II"; Transporte de matérias perigosas; Ordenamento do território; Protecção civil.

\section{RESUMEN}

Evaluación e control de riesgos químicos graves e la protección civil, en el transporte e en la Directiva "SEVESO II" - Esta comunicación presenta las modalidades de actuación de la Autoridad Nacional de Protección Civil (ANPC) de Portugal y las entidades públicas y privadas en el contexto del sistema de protección civil, preparadas para afrontar los riesgos colectivos derivados de la transportación de mercancías peligrosas y de las instalaciones fijas con productos químicos (Directiva "SEVESO II" 96/82/EC), en la gestión de emergencias y desastres y la evaluación y cartografía de los riesgos químicos graves, en su prevención, preparación, planificación y adecuación de la gestión del territorio.

Palabras clave: Riesgos químicos graves; Directiva "SEVESO II"; Transporte de mercancías peligrosas; Control de la urbanización/ Ordenación del territorio; Protección civil.

\section{RESUMÉ}

Evaluation et contrôle des risques chimiques majeures et la protection civile, dans le transport de matières dangereuses et dans les installations au abri de la Directive "SEVESO II" - Cette communication présente les modalités d'organisation de l'Autorité Nationale de Protection Civile (ANPC) du Portugal et les entités publiques et privées dans le cadre du système de protection civile, prêt à faire face aux risques collectifs découlant du transport de matières dangereuses et les installations fixes avec des produits chimiques (couvert par la Directive « SEVESO II » 96/82/EC), dans la gestion des urgences et des catastrophes et de l'évaluation et la cartographie des risques chimiques graves dans leur prévention, la préparation, la planification et l'adéquation de la gestion du territoire.

Mots-clé: Risques chimiques majeures; Directive SEVESO II; Transport de matières dangereuses; Maîtrise de l'urbanisation/ L'aménagement du territoire; Sécurité civile.

\section{ABSTRACT}

Assessment and control of major chemical hazards and the civil protection, in the transportation and the Directive "SEVESO II" - This communication discusses the instruments for major chemical risk reduction available to the Portuguese National Authority for Civil Protection (ANPC), public and private entities in the context of the civil protection system. The article highlights the implementation in Portugal of major chemical risk reduction measures such as emergency and disaster management and planning, risk assessment, mapping, prevention, preparedness and land use planning, related to the transportation of dangerous goods and the establishments subject to the European Directive "SEVESO II" 96/82/CE.

Key words: Major chemical hazards; European Directive "SEVESO II"; Transportation of dangerous goods; Land use planning; Civil protection.

\footnotetext{
* O texto deste artigo corresponde à comunicação apresentada ao II Congresso Internacional de Riscos e VI Encontro Nacional, tendo sido submetido para revisão em 01-06-2010, tendo sido aceite para publicação em 12-08-2010. Este artigo é parte integrante da Revista Territorium, $n .^{\circ} 18,2011$, ${ }^{\circledR}$ RIscos, ISBN: 0872- 8941.
} 
Sumário

O objectivo fundamental da Autoridade Nacional de Protecção Civil (ANPC) é proporcionar a segurança de pessoas, ambiente e bens. Tirando partido das ferramentas de avaliação e de redução de riscos, a Autoridade procura fomentar a aplicação de políticas de prevenção e de protecção de uma forma integrada e proporcional, valorizando o envolvimento das autoridades municipais.

Neste documento identificam-se as funções de protecção civil e formas de actuação da ANPC, das entidades públicas e privadas e dos agentes e serviços de protecção civil face aos riscos colectivos decorrentes do transporte de matérias perigosas e das instalações fixas com produtos químicos (abrangidos pela Directiva "SEVESO II" 96/82/CE).

Ao nível da prevenção, destaca-se a intervenção da ANPC na elaboração e revisão dos instrumentos de gestão do território. Neste âmbito, a Autoridade vindo a integrar as comissões de acompanhamento dos planos municipais de ordenamento do território com o objectivo de serem consideradas distâncias de segurança ao redor de indústrias perigosas.

Também ao nível da avaliação dos riscos, a ANPC vem promovendo a melhoria da caracterização dos riscos e dos elementos expostos vulneráveis aos riscos químicos graves. A apreciação dos planos municipais de emergência de protecção civil, de carácter geral e especial, em conjunto com os planos de emergência externos da Directiva "SEVESO II", tem permitido difundir orientações para a identificação, georeferenciação e caracterização das fontes de perigo e dos elementos vulneráveis.

Esta comunicação apresenta, na perspectiva dos riscos químicos graves, a estrutura organizacional preparada pelo Estado que incorpora autoridades políticas, instrumentos legais e autoridades técnicas e administrativas. Esta organização intervém na gestão das emergências e das catástrofes e nas políticas de prevenção e de preparação, com o objectivo da segurança das populações.

\section{Introdução}

As actividades económicas que lidam com produtos químicos são diversas e as quantidades de produtos químicos envolvidos são devidas às possibilidades tecnológicas iniciadas pela revolução industrial e pela apetência dos consumidores e da sociedade em geral por produtos variados e energia barata e abundante.

Actualmente contam-se cerca de 160 estabelecimentos abrangidos pela Directiva "SEVESO II" (transposta para o direito interno pelo Decreto-Lei n. ${ }^{\circ}$ 254/2007) em Portugal, aproximadamente 60 dos quais de nível superior de perigosidade. Estas distribuem-se por instalações da indústria química, petroquímica, petrolífera, de combustíveis gasosos, de explosivos, de adubos químicos, de herbicidas e pesticidas para a agricultura, de indústrias que utilizam produtos químicos como matéria-prima ou reagente, entre outras.

Assim o confirmam também os indicadores do Instituto Nacional de Estatística (INE) que apontam para que o transporte de mercadorias perigosas por estrada seja da ordem da dezena de milhão de toneladas por ano. Perto de dois terços são constituídos por combustíveis líquidos e gasosos e o restante por cerca de seis dezenas de outros produtos químicos em cisterna (inquérito do Serviço Nacional de Protecção Civil - SNPC), havendo ainda mais variedade em outros tipos de reservatórios.

Sendo actividades que não estão isentas de riscos, ocorrem acidentes em Portugal, que se estimam, mesmo sem dispor de informação completa, em mais de vinte acidentes por ano, contando somente com aqueles em que há uma participação efectiva da mercadoria perigosa.

Um RIsco, de uma forma geral, considera uma qualquer situação que comporta alguma incerteza e que pode resultar em prejuízo. Na especificidade da protecção civil, presta-se atenção às possibilidades de ocorrência de acontecimentos indesejáveis (acidentes), com origem num fenómeno natural ou numa actividade humana, com potencial para expor pessoas, o ambiente ou bens materiais a perigos graves que possam provocar consequências extremamente negativas.

O interesse da ANPC pelas actividades económicas associadas aos riscos químicos graves explica-se pela necessidade de promover as actividades do Estado, partilhada pelas empresas e os cidadãos, com a finalidade de reduzir os riscos colectivos inerentes a situações de acidente grave ou catástrofe, de forma a contribuir para se atingirem níveis de risco suficientemente baixos que permitam o usufruto de uma vida em segurança aos indivíduos e um desenvolvimento sustentável à sociedade, por outras palavras, a PROTECÇÃO CIVIL.

\section{Avaliação dos riscos}

De acordo com a avaliação dos riscos no transporte de mercadorias perigosas e em instalações fixas, os eventos com potencial de provocar um ACIDENTE GRAVE OU CATÁSTROFE podem ser classificados de acordo com a seguinte tipologia:

- Rebentamento do recipiente, eventualmente acompanhado de bola de fogo, se a matéria for inflamável,

- Explosão de uma nuvem de vapores de líquidos ou gases, inflamáveis, potencialmente perigosa se ocorrer em espaços confinados (esgotos, caves, etc.), 
- Incêndio de vapores de líquidos ou gases inflamáveis, podendo acarretar vítimas mortais se envolver pessoas na imediação do derrame ou da fuga,

- Libertação de gases ou vapores tóxicos de reservatórios (ou válvulas ou tubagens de cisternas danificadas), viabilizando a sua inalação ou

- Disseminação, no ambiente, de outros tipos de carga poluidora.

Em termos gerais, os fenómenos perigosos que se manifestam neste tipo de acidentes (a onda de pressão, a radiação térmica e os projécteis duma explosão ou dum rebentamento, a radiação térmica e fumos nocivos de incêndios, a toxicidade de nuvens ou derrames tóxicos, de entre outros) possuem a capacidade de provocar efeitos nocivos de grau diverso, dependentes da quantidade e do tipo de matérias envolvidas e do grau de vulnerabilidade das pessoas e dos elementos ambientais expostos na envolvente do local do acidente.

Empiricamente, constituem emergências de protecção civil as situações que requerem a intervenção e a coordenação das equipas de socorro e eventual tomada de medidas de protecção das populações afectadas.

Certas substâncias e preparações químicas podem também possuir propriedades radioactivas, sendo que nos perigos das radiações ionizantes, o tipo de riscos de acidente grave ou catástrofe mais significativo, o risco de acidente nuclear, não atinge, em Portugal, um nível tão elevado como nos países que operam centrais de produção de energia eléctrica com energia nuclear. A recepção precoce do alerta, incluindo a vigilância da radioactividade do ar pela Agência Portuguesa do Ambiente (APA), tem sido objecto de atenção especial. Concretizaram-se também outras formas de preparação para a emergência, por exemplo, no Plano de Emergência de Protecção Civil especial para Navios de Propulsão Nuclear no Rio Tejo (SNPC, 1998) e no Manual de Intervenção em Emergências Radiológicas (ANPC, 2009).

Existem ainda outros tipos de riscos de natureza semelhante, como por exemplo a ameaça de armas Nucleares, Radiológicas, Biológicas ou Químicas (NRBQ) que, tratando-se de eventos lesivos de carácter intencional, a prevenção deste tipo de ameaças situa-se na área da Defesa Nacional, dos Serviços de Informações e da Segurança Pública, sendo a actuação da protecção civil complementar. Dada a necessidade de protecção da população em caso de acção de guerra ou terrorista, promove-se a interligação do sistema de protecção civil com os domínios da segurança pública, ao nível da preparação para a resposta a emergências, através da participação da ANPC em exercícios simulados de emergências deste tipo sejam de âmbito nacional ou internacional, no seio da União Europeia ou da Organização para o Tratado do Atlântico Norte (OTAN).

O risco nuclear também não será aqui especificamente abordado, privilegiando-se neste texto os tipos de risco químicos graves associados a matérias perigosas transportadas ou em instalações fixas que constituem fonte de perigo de acidente grave ou catástrofe com origem no próprio território nacional.

\section{Formas de reduzir os níveis de risco}

Sem entrar em detalhe, podem reduzir-se os níveis de risco tanto colocando em prática medidas (fig. 1) que PREVINAM (evitem) a ocorrência ou reduzam a extensão dos efeitos dos fenómenos perigosos, ou PROTEJAM as pessoas, o ambiente e os bens materiais, impondo separação (sejam barreiras, distância física ou tempo de fuga) entre tais fenómenos e os elementos expostos.

\begin{tabular}{ll}
$\begin{array}{l}\text { Conhecimento } \\
\text { dos fenómenos }\end{array}$ & $\begin{array}{l}\text { Informação da } \\
\text { população }\end{array}$ \\
\hline
\end{tabular}

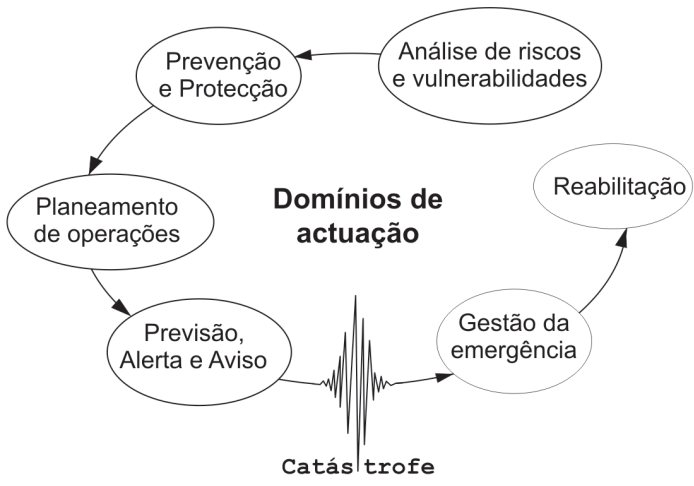

Fig. 1 - Campos de actuação da protecção civil.

O Estado Português obriga-se a assegurar a execução de várias medidas de PREVENÇão, tendo em conta o ambiente envolvente ao potencial local de acidente (condições atmosféricas e a vizinhança do mesmo).

No caso do transporte por estrada, são exemplos de medidas preventivas:

- O planeamento da capacidade de tráfego, avaliação dos riscos inerentes a alterações profundas de utilização da via, manutenção, projecto de engenharia da via, sinalização, aplicadas sobre a infra-estrutura viária;

- O código da estrada, a fiscalização, a formação e certificação dos condutores, geral e especial, para o transporte de mercadorias perigosas), relativas ao condutor e utentes da via;

- A concepção, manutenção e inspecção dos veículos; e 
- No caso do transporte de matérias perigosas, também a normalização, ensaio, certificação de conformidade e aprovação impostos pelo Estado (RPE, 2008) sobre reservatórios e equipamentos de enchimento e descarga, e manutenção e inspecção assídua geral com ênfase acrescida nas empresas que operam no sector.

Quanto às medidas de prevenção relativas ao transporte ferroviário, poder-se-á encontrar um elevado grau de analogia na regulamentação aplicável.

O transporte em conduta ("pipeline"), tendo como uma das causas de acidente mais frequente a rotura desta por máquinas de movimentação de terras, encontra como medidas preventivas mais visíveis: a sinalização à superfície e subterrânea do tubo, o aumento da espessura do mesmo e outras protecções adicionais em zonas diferenciadas segundo a ocupação da envolvente, as restrições de utilização da vizinhança imediata da conduta (servidões) e a monitorização e inspecção periódica das instalações e tubagens.

As medidas preventivas relativas às instalações fixas são mais variadas, dada a diversidade de indústrias de transformação e de armazenagem e o tipo de matérias perigosas envolvidas. Por essa razão, a legislação aponta para a utilização de metodologias de análise de risco com vista a conceber ou alterar, de uma forma segura e fiável, os processos de transformação e outros procedimentos de operação, incorporando o saber das ciências aplicadas, da engenharia e do conhecimento empírico dos profissionais da empresa.

Por exemplo, o estudo dos riscos ou até a própria procura de rentabilidade pode conduzir a alterações de processos ou de modos de operação que incluam a redução da probabilidade de ocorrência ou do grau de danos potencial em caso de acidente, tais como:

- A escolha de solventes menos inflamáveis ou tóxicos,

- A redução de quantidades armazenadas das matérias mais perigosas,

- A redução da severidade das condições de operação, de pressão ou de temperatura,

- O inventário de equipamentos críticos e a sua manutenção preventiva,

- A consciencialização do risco dos trabalhadores, incluindo a direcção do estabelecimento, por exemplo, participando nos estudos de risco, e

- A instalação de bacias de retenção associadas aos depósitos e de outras medidas de contenção de derrames.

Note-se que a elaboração de um relatório de segurança com base em análises de risco das instalações é obrigatória desde 1987 para um conjunto de estabelecimentos seleccionados. Na vigência da Directiva "SEVESO II" de 1996, actualmente transposta para o direito nacional pelo Decreto-Lei n. ${ }^{\circ}$ 254/2007 de 12 de Julho, a manutenção das condições de segurança face a acidentes químicos graves é assegurada por inspecções efectuadas pelas autoridades públicas e pela imposição legal aos responsáveis pelos estabelecimentos de nível superior de perigosidade da aplicação continuada de sistemas de gestão de segurança para aplicação da política de prevenção de acidentes graves, adequados aos riscos presentes, sujeitos a auditorias externas anuais credenciadas pelas autoridades públicas.

As medidas de PROTECÇão podem ser estáticas e permanentes (protecção passiva) ou podem ser desencadeadas no momento da ocorrência dum fenómeno perigoso (protecção activa).

Tal como as medidas de prevenção, as de PROTECÇÃo PASSIVA também actuam sobre a infra-estrutura viária, sobre os utentes da via e sobre todos os componentes do veículo.

No caso do transporte de mercadorias perigosas, muitas medidas são do conhecimento do público em geral tais como, por exemplo:

- A recomendação ou a imposição de restrições aos itinerários e horários de certos transportes de mercadorias perigosas para evitar as elevadas concentrações de pessoas na via (pelos congestionamentos de tráfego) ou na sua vizinhança imediata (nas margens urbanizadas),

- A redução de obstáculos rígidos (indeformáveis) nas margens das estradas,

- As proibições de atravessamento de zonas urbanas por veículos de transporte de matérias perigosas, quando possíveis, e

- As proibições de estacionamento de veículos na proximidade de locais de habitação, de passagem ou de reunião da população e de estradas públicas.

A ANPC tem vindo a colaborar na produção legislativa e na elaboração e revisão dos instrumentos de gestão do território, contribuindo para a consideração explícita dos riscos químicos graves e com o objectivo da introdução de critérios de limitação dos riscos e dos danos humanos (Mondril N. e Vicêncio H., 2009).

\section{Prevenção e protecção pelo ordenamento do território}

O Estado também tem obrigações directas no campo das instalações fixas no domínio das medidas de protecção passiva, acentuando-se a importância da actuação dos instrumentos de ORDENAMENTO DO TERRITóRIO, de forma a:

Escolher o local adequado aos novos estabelecimentos e 
- Limitar a ocupação da vizinhança dos de maior risco, pela urbanização e outras formas de ocupação posteriores.

Encontram-se também nos instrumentos de gestão territorial critérios e recomendações de limitação de ocupação do solo nas margens de vias com tráfego significativo de mercadorias perigosas.

No campo das instalações fixas, as obrigações impostas pela Directiva "SEVESO II" (de 1996) impõem às autoridades municipais o conhecimento dos riscos graves prévio à tomada de decisão de opções de gestão territorial de forma a garantir as distâncias de separação que previnam riscos graves.

Os países Europeus aplicam estas medidas de forma diversa. Em todos, a definição das distâncias de separação tem em conta os alcances de efeitos letais e de danos irreversíveis sobre a saúde das pessoas que as modelações dos fenómenos perigosos permitem antever. A forma como é graduada a importância a dar aos diversos tipos de cenários de acidente grave varia, havendo abordagens mais quantitativas, recorrendo exaustivamente a estimativas de probabilidades, e abordagens semi-quantitativas, que recorrem a informação sobre a frequência de acidentes análogos, avaliação dos estudos de segurança, entre outros.

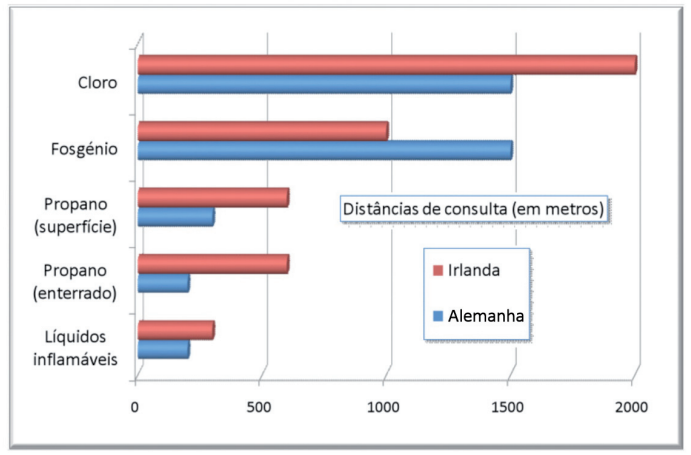

Fig. 2 - Distâncias de consulta.

Os processos de aprovação de planos de ordenamento e de operações urbanísticas diferem consoante as arquitecturas legais dos países da União Europeia. Para muitos, numa fase preliminar, estabelece-se uma "zona de consulta" (Fig. 2) em redor de cada estabelecimento existente abrangido pela Directiva "SEVESO II", para além da qual se excluirá consulta. Este método, aplicado a Portugal, conduzirá a que, na zona de consulta, a autoridade pública competente nesta matéria será consultada sobre a razoabilidade da construção ou ampliação de zonas residenciais, estabelecimentos ou recintos que recebam público ou outras formas de aumento da população externa exposta aos riscos químicos graves da empresa "Seveso".

Além dos critérios quantitativos a implementar em Portugal, as obrigações legais de informação da população sobre os riscos químicos graves a que estão sujeitos abrem perspectivas e lançam o desafio da concretização dum desenvolvimento sustentável com base no conhecimento.

$\mathrm{Na}$ legislação de países europeus, encontram-se ainda acções que procuram compensar os perigos remanescentes e reforçar a protecção das pessoas na envolvente. Essas medidas, associadas a diversas distâncias de separação, são passíveis de ser adoptadas em partes, na totalidade ou nas imediações da "zona de consulta", e podem estipular especificações de redução da vulnerabilidade:

a) À radiação térmica de incêndios exteriores, com a utilização de materiais resistentes e a definição de uma área de refúgio/ abrigo em cada edifício;

b) À sobrepressão de explosões exteriores, com a limitação das superfícies vidradas, nos edifícios novos, e o reforço da resistência das vidraças, nos edifícios existentes;

c) A nuvens tóxicas, com contenção do ar interior dos edifícios, de forma a providenciar refúgio dos ocupantes nas zonas de maior risco, nas áreas dificilmente evacuáveis em tempo útil, em especial para estabelecimentos com população vulnerável, os que recebem público e, se bem com requisitos simplificados, para as habitações.

Nas zonas de maior risco, também se encontra a obrigatoriedade de constarem, no contrato de aquisição ou de aluguer, sob pena de nulidade do mesmo: os perigos a que a propriedade e as pessoas estão sujeitas e o facto da mesma estar situada na zona de consulta do estabelecimento "SEVESO".

As medidas estruturais prescritas nos instrumentos de gestão territorial seriam posteriormente interligadas com o plano de emergência externo, nomeadamente quanto à informação da população susceptível aos riscos, as medidas a adoptar e as formas comunicação de início e de fim de aviso e de alerta, de confinamento ou de evacuação.

Mas, mesmo assim, os acidentes acontecem ...

Foram referidas as medidas de PROTECÇão estáticas (protecção passiva), apontando-se de seguida aquelas que são desencadeadas no momento da ocorrência dum fenómeno perigoso (protecção activa), seja com recurso a sistemas automáticos ou à intervenção humana.

As medidas de PROTECÇÃo ACTIVA aplicam-se, como as anteriores, aos vários elementos do ambiente rodoviário, lembrando-se aqui somente, para o transporte de mercadorias perigosas, o equipamento de protecção do condutor, os extintores, as fichas com instruções 
de actuação na emergência e, outra vez, a formação especial dos condutores, neste caso para a primeira intervenção nos acidentes, etc..

Destacam-se também algumas medidas deste tipo que requerem actuação imediata de serviços e agentes de protecção civil, no momento da emergência:

- A supressão, controlo ou redução da extensão do fenómeno perigoso,

- A interdição de acesso a locais perigosos e

- A evacuação de pessoas ou refúgio em compartimentos isoláveis.

Estas últimas medidas de protecção activa e aquelas que se destinam a reduzir os danos sofridos por pessoas e pelo ambiente, causados pelo acidente já consumado, seja o desencarceramento de vítimas, primeiros socorros e evacuação primária (de vítimas para as urgências hospitalares), para os primeiros, ou a limpeza e recolha de poluentes, para o segundo, constituem as acções de RESPOSTA À sitUação de EMERGÊNCIA.

Associada ao acidente, a emergência comporta também a necessidade de controlo do tráfego e investigação técnica e criminal, entre outras.

No caso das instalações fixas, a empresa tem obrigações acrescidas, por exemplo, na protecção dos trabalhadores e outras pessoas presentes no estabelecimento, sendo sua a responsabilidade da supressão, controlo ou redução da extensão do fenómeno perigoso.

Tanto por iniciativa do industrial como através da progressiva regulação pelas autoridades públicas, tem-se tornado explícita a necessidade de manter procedimentos escritos de operação em situação normal e em casos de emergência e, em geral, planear e organizar os meios para dar resposta a situações de acidente. Concretizados na lei, são exemplos: os planos de emergência internos para algumas instalações fixas (de alto risco), os planos de segurança e emergência dos gasodutos e oleodutos, as obrigações análogas do regulamento para o transporte de mercadorias perigosas e do regulamento de segurança contra incêndios em edifícios.

\section{O soar do alarme}

Para que as medidas de protecção activa e de resposta à emergência em geral sejam eficazes, torna-se necessário que os serviços de emergência sejam ALERTADos aquando da ocorrência dum acidente, de forma a poderem responder, mobilizando os meios necessários para socorrer as vítimas e proteger o ambiente.

Em todos os casos de acidente grave que possam ocorrer no ambiente rodoviário, os serviços de emergência dependem em primeiro lugar do alerta (fig. 3 ) do cidadão

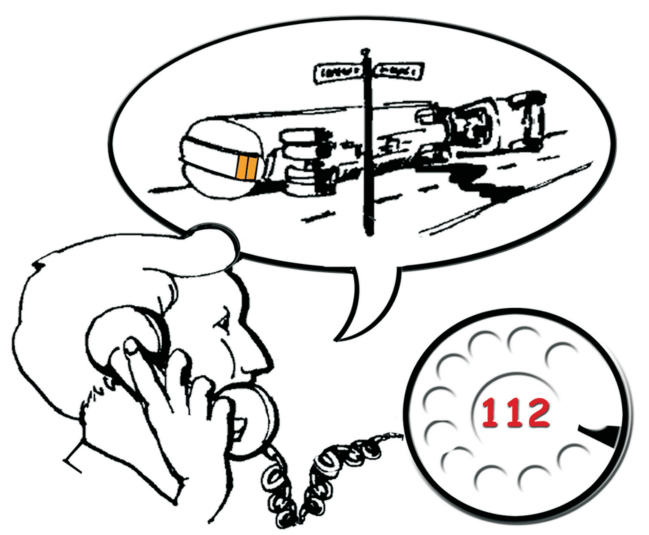

Afaste-se do local do acidente com mercadorias perigosas, pelo menos $1 \mathrm{~km}$, antes de parar para alertar as autoridades

Fig. 3 - Ilustração sobre o alerta inicial.

utente da via de trânsito para tomar conhecimento do acidente ou duma situação perigosa e das suas circunstâncias específicas.

Actualmente, a recepção do alertaé feita telefonicamente pelas centrais “112” (Número de Emergência Europeu), operadas pela PSP e pela GNR, e pelas centrais das empresas concessionárias das auto-estradas (BRISA, etc.) e do organismo público Estradas de Portugal (EP, ex-JAE) que escutam os postos "SOS" das auto-estradas e itinerários principais, fazendo o encaminhamento das chamadas consoante o tipo de situação. As urgências de criminalidade são dirigidas para as forças policiais e os incêndios e inundações para os corpos de bombeiros.

As chamadas de urgência médica são encaminhadas para os Centros de Orientação de Doentes Urgentes (CODU) do Instituto Nacional de Emergência Médica (INEM) de Faro, Coimbra, Lisboa e Porto, ali se avaliando o estado da vítima, prestando aconselhamento imediato e mobilizando o meio de socorro credenciado mais adequado, sejam ambulâncias, viaturas médicas de emergência e reanimação (VMER) ou helicópteros de emergência médica, por exemplo.

No caso das instalações fixas, industriais e de armazenagem, antecipa-se que o alerta provenha em primeiro lugar dos responsáveis pelo estabelecimento em causa, cuja obrigação legal encontra-se claramente definida pela Directiva "SEVESO II". O transporte em conduta depende, dada a dispersão espacial, tanto da rede de alerta pública como da instrumentação de detecção de fugas operada pelas empresas proprietárias. No transporte de mercadorias perigosas por estrada ou por caminho-de-ferro, espera-se do condutor ou da tripulação a iniciativa de executar uma primeira intervenção no sentido de conter o problema (nos casos previstos nas fichas de segurança), aconselhar o afastamento das pessoas próximas e alertar os serviços de socorro. 


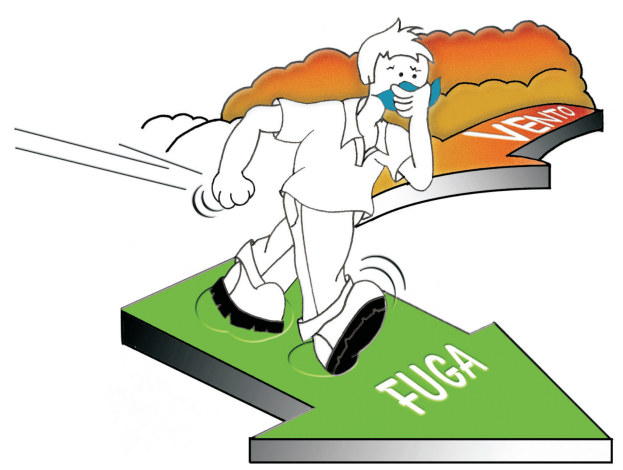

Se for atingido fora de casa por uma nuvem de gás ou de fumo: - Respire através dum lenço molhado (até se encontrar protegido pelo vento); e

- Afaste-se perpendicularmente ao vento, pela estrada, para um local mais elevado

Fig. 4 - Medidas de autoprotecção (fora de casa).

Em caso de suspeita de intoxicação ou por precaução antes de tocar em vítimas contaminadas com matérias perigosas (roupa ensopada, pó espalhado, etc.), existe também a possibilidade de obter aconselhamento médico especializado por telefone do Centro de Informação Anti-Venenos (808250143 - CIAV do INEM).

\section{Actuação dos serviços de protecção civil em emergências}

A ANPC, através dos comandos distritais de operações de socorro (CDOS) e do comando nacional de operações de socorro (CNOS), comanda os corpos de bombeiros ao nível distrital e nacional, acompanhando as emergências do quotidiano.

Tornam-se necessárias tarefas de coordenação e apoio logístico dos CENTROS DE COORDENAÇÃo DE OPERAÇÕES (cCO) e de coordenação e decisão política das COMISSÕES DE PROTECÇÃO CIVIL somente em situações de emergência que excedam certa dimensão ou complexidade. É certamente o caso quando as operações se prolongam no tempo com as respectivas restrições à vida da comunidade ou quando a vulnerabilidade da população potencialmente afectável aconselha prever necessidades imediatas de abrigo e outras de reabilitação.

Em situações extremas, os RESPONSÁvEIS políticos DE PROTECÇÃO CIVIL (Presidente da Câmara Municipal, Governador Civil, Presidente do Governo Regional ou Primeiro Ministro) e os responsáveis por meios e recursos necessários, constituem os referidos centros de coordenação de operações. A ANPC e restantes SERVIÇOS DE PROTECÇ̃̃o CIVIL mantêm os espaços físicos, corpo técnico, a informação e os meios de comunicação necessários para apoiar a direcção das acções de emergência.

Por ordem dos mesmos responsáveis, podem ser activados OS PLANOS DE EMERGÊNCIA DE PROTECÇÃo CIVIL do nível territorial respectivo (municipal, distrital, regional ou nacional), nos quais estão detalhadas as tarefas e responsabilidades de cada organismo, tendo em conta os riscos presentes na área territorial em causa e as operações de mitigação previsíveis face aos cenários de acidente considerados.

Específicos para os tipos de risco aqui abordados, existem planos de emergência de protecção civil especiais para riscos químicos graves (planos de emergência externos) em oito municípios que abrangem uma vintena de estabelecimentos industriais ou de armazenagem. Os cinco planos que se encontram formalmente aprovados pela Comissão Nacional de Protecção Civil foram elaborados por iniciativa do SNPC em apoio às câmaras municipais, tendo recebido colaboração dos vários agentes e serviços locais, dos industriais e do SNPC através das suas delegações distritais e serviços centrais. Estes planos têm em conta os potenciais acidentes graves que possam advir das operações nas instalações, incluindo as de carga e descarga, efectuadas nos estabelecimentos abrangidos e do transporte de mercadorias perigosas, especialmente aqueles que têm origem ou destino nos complexos industriais e nos municípios em causa. Os testes, simulacro e exercícios dos planos são também obrigação constante da lei.

O RECONHECIMENTO pelas autoridades de protecção civil da necessidade de desencadear acções de coordenação compreende a avaliação da situação, a triagem e o alerta feitos pelos serviços de emergência no terreno. A informação inicial que conduz à detecção da situação de emergência de protecção civil parte, a maioria das vezes, das centrais " 112 " ou a partir dos elementos duma corporação de bombeiros (que avançaram para acções de socorrismo, desencarceramento, combate a incêndio ou controlo de poluição).

Conforme os casos, os serviços de protecção civil recorrem a outras fontes para completar a análise da situação. Os acidentes com matérias perigosas carecem em especial da contribuição das empresas operadoras do transporte ou dos estabelecimentos industriais, nomeadamente pelo conhecimento do comportamento das matérias e dos equipamentos de que dispõem.

Além dos agentes de protecção civil já referidos, também pode haver lugar para o acompanhamento da situação pelo serviço municipal, precedendo à activação do respectivo centro de operações ou outra actuação de coordenação relacionada. Complementando os serviços municipais, a ANPC acompanha as ocorrências que, pelas suas características, possam potenciar um acidente grave, através dos seus serviços distritais (comandos distritais de operações de socorro), que avaliam a necessidade de prestar apoio, por vezes deslocando-se ao local. O comando nacional de operações de socorro da ANPC comanda, coordena ou colabora com estes 
suplementando a capacidade de recolha de informação e prestando aconselhamento técnico, quando necessário.

Sendo os acidentes químicos raramente previsíveis e não atingindo normalmente dimensões que prolonguem no tempo as operações de emergência, outros meios da ANPC serão pouco frequentemente postos no terreno, como sejam uma Equipa de Reconhecimento e Avaliação da Situação (ERAS - para consolidação de dados e meios a mobilizar) ou outros constantes dos planos distritais e nacionais.

Na generalidade dos acidentes em estrada e arruamentos, não considerando o normal controlo de tráfego, sempre necessário quando ocorre um acidente rodoviário, apenas nos casos em que a emergência se prolonga poderá ser considerado o AVISO À POPULAÇÃo (utentes da via de trânsito ou população envolvente) que comporte alguma recomendação de protecção mais específica (afastamento do local, interdição de entrada em zona perigosa, refúgio no domicílio, controlo sanitário, etc.), sendo esta uma decisão da responsabilidade da autoridade de protecção civil. Nos casos em que a informação técnico-científica aconselhar, por precaução, logo numa fase precoce, o afastamento de pessoas e veículos, os elementos das forças policiais podem iniciar a evacuação das zonas públicas até à distância recomendada, informando de imediato as autoridades responsáveis de protecção civil.

Em zonas consideradas prioritárias, com elevada frequência de certos transportes e com elevadas concentrações demográficas e na envolvente das instalações de alto risco, podem ser integrados, nos planos de emergência de protecção civil, procedimentos de autoprotecção pré-definidos. Estes devem ser treinados regularmente e praticados com a população vizinha, conforme os cenários de acidente que o processo de avaliação dos riscos e a análise das vulnerabilidades tenha sugerido.

Em zonas vulneráveis à libertação de nuvens tóxicas, pode mesmo justificar-se a implantação de sistemas de aviso rápido. Estes requerem meios de detecção adequados, acompanhamento humano com capacidade de decisão e meios de difusão de sinais sonoros conhecidos, altifalantes em viaturas das forças policiais, rádios locais com subsequente informação complementar, entre outros.

Por exemplo, no caso duma cisterna com mercadorias perigosas danificada que se imobiliza na estrada, e em que o responsável pelo controlo da situação considere que a operação de trasfega ou de reposição da carga comporte riscos de consequências graves para a população envolvente, o Presidente da Câmara Municipal, ou alguém por ele credenciado, pode requisitar empenhamento de meios específicos e apoio logístico, para assegurar o afastamento de pessoas do local ou a limitação duma eventual poluição.

Pode mesmo ser necessário associar às equipas encarregues da normalização da carga perigosa (contenção de fugas, recolha da carga espalhada em veículos capazes de a retirar, etc.) que trabalham junto ao local do acidente:

- Pessoal com equipamento que detecte e meça as concentrações no ar de eventuais nuvens de vapores ou gases tóxicos ou inflamáveis ou os níveis de poluentes no ambiente,

- Especialistas que avaliem a perigosidade da situação para as pessoas ou o impacto no ambiente,

- Responsáveis pela direcção das operações de protecção civil que tenham poder para expandir uma zona interdita ao público, modificá-la e anulá-la logo que desnecessária e

- Equipas que transmitam as mensagens de aviso à população para adoptar medidas de autoprotecção (procurar refúgio em casas ou zonas seguras, evacuar áreas temporariamente perigosas, etc.) $E$ que persuadam e auxiliem as pessoas a seguir os conselhos difundidos.

\section{Comunicação dos riscos}

A ANPC vem desempenhando um papel central de sistematização, normalização e difusão de boas práticas junto das várias áreas administrativas e territoriais e, através destas, à população.

No âmbito dos riscos químicos graves, aponta-se a edição do "Guia da informação para a elaboração de plano de emergência externo (Directiva "SEVESO II")" (ANPC, 2008), que estabelece em normas as boas práticas de avaliação quantificada dos impactos dos cenários de acidente químico grave e sua comunicação em suporte informático e cartográfico (Fig. 5).

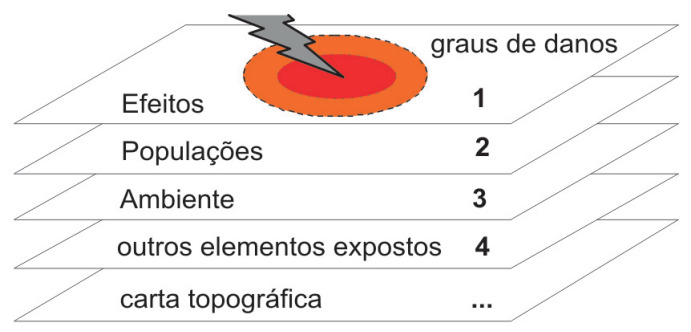

Fig. 5 - Cartografia do impacto dos cenários de acidente dos efeitos perigosos.

No sentido da melhoria da percepção dos riscos químicos graves, tanto no processo de planeamento, como pelo público em geral, salienta-se o trabalho de substituição de antigos parâmetros técnicos díspares por uma 
normalização com base em conceitos com que o cidadão pode sentir facilmente quais as intensidades das agressão à sua integridade física, iniciada pelo SNPC em 2001 e institucionalizado por força do Decreto-Lei n. ${ }^{\circ}$ 254/2007 e pelo Guia da ANPC em 2008 acima mencionado.

Nesse Guia, definem-se os processos de cálculo e de representação das áreas territoriais (Fig. 6) com população vulnerável aos efeitos dos acidentes químicos graves escalonadas em três graus de danos para a saúde das pessoas, isto é, onde um indivíduo (mesmo aqueles susceptíveis, como as crianças, idosos, etc.) pode vir a sofrer:

A. Efeitos na saúde com perigo de MORTE;

B. Efeitos na saúde IRREVERSÍVEIS, prolongados ou de outra forma graves ou sintomas que possam diminuir a capacidade para tomar as medidas de auto-protecção adequadas;

C. Efeitos na saúde ligeiros e TRANSIENTES (que não permanecem após a cessação das manifestações perigosas) ou experiência de irritação ou desconforto notórios.

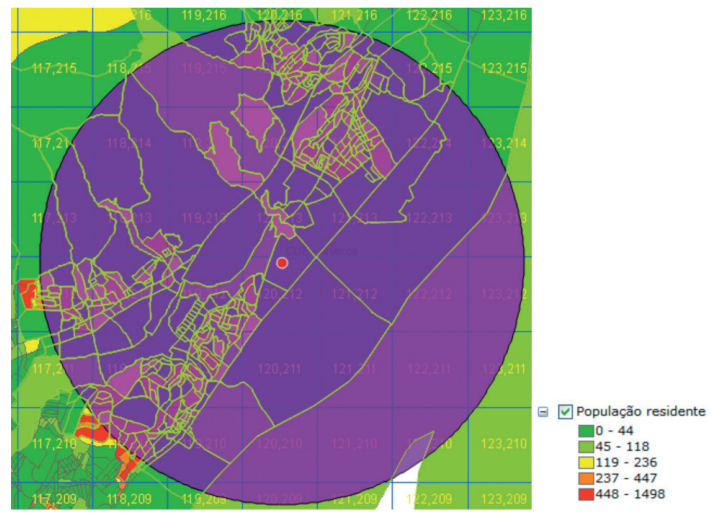

Fig. 6 - Ilustração de uma área vulnerável, com recursos a sistemas de informação geográfica.

Com vista à difusão de informação credenciada e normalizada, a ANPC também tem produzido folhetos relativos à identificação dos perigos nas etiquetas, rótulos e placas dos produtos químicos e mercadorias perigosas e comportamento a adoptar pelas pessoas em caso de acidente (exemplo na Fig. 7).

De âmbito geral, mas contendo também uma vertente especial para os riscos químicos graves, a ANPC preparou materiais informativos e, em colaboração com o Ministério da Educação, dinamiza, apoia e acompanha os mais de 300 Clubes de Protecção Civil que funcionam nas escolas. No âmbito do sistema de protecção civil, cabe aos serviços municipais de protecção civil (SMPC) a informação às populações sobre os riscos de acidente grave ou catástrofe, sobre os mecanismos preparados para os minimizar e as medidas de autoprotecção e sobre os comportamentos que devem adoptar.

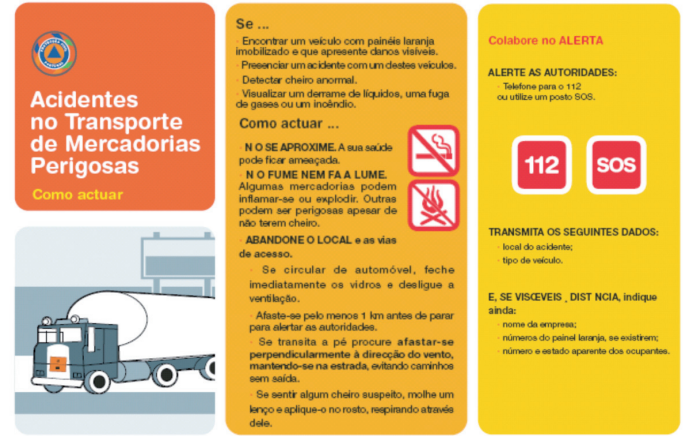

Fig. 7 - Folheto relativo ao transporte de mercadorias perigosas.

Relativamente às vias de difusão de informação associadas aos planeamento de emergência, a ANPC vem promovendo a melhoria e regulando a caracterização dos riscos e dos elementos expostos vulneráveis aos riscos químicos graves. A apreciação pela ANPC dos planos municipais de emergência de protecção civil, de carácter geral e especial, como os planos de emergência externos da Directiva "SEVESO II", tem permitido difundir orientações tanto no processo de identificação e a caracterização das fontes de perigo como dos elementos vulneráveis e correspondente geolocalização em cartas de risco.

É de apontar ainda que os SMPC vêem estas suas obrigações relativas aos riscos químicos graves, no âmbito dos planos de emergência externos, apoiadas pelas definições legais sobre a informação à população e a consulta pública emprestadas pela Directiva "SEVESO II".

\section{Considerações finais}

Há muito tempo que é comummente aceite que, somente com o conhecimento empírico que cada pessoa ganha com a repetição de tarefas, não se atingem os níveis de segurança pretendidos. A rapidez de mutação da sociedade contemporânea, com a rápida evolução dos processos, as novas tecnologias emergentes e as frequentes mutações das relações de comércio e do trabalho incrementam mais ainda necessidades de organização e planeamento. Antes como agora, só se atingem níveis de segurança elevados quando existe tomada de decisão com base no conhecimento, participação e responsabilização dos intervenientes, transparência de critérios e acompanhamento da aplicação das decisões para avaliação da eficácia e correcção de rumo.

O sistema de protecção civil, com início há trinta anos e com lei de bases há quinze, e a Autoridade Nacional de Protecção Civil, procuram desempenhar as suas funções de forma útil e integradora. De outra forma não poderia ser, dada a essencial cooperação entre os organismos do Estado, cidadãos, suas associações e empresas. 
Constrói-se a protecção civil como um espaço de diálogo e solidariedade para a eficaz aplicação de medidas preventivas, de protecção, para a detecção e avaliação dos riscos e respectivas vulnerabilidades, e nos aspectos mais visíveis e mediáticos, como o alerta, a gestão da emergência, planos de emergência, avisos à população e sensibilização sobre os riscos.

\section{Referências}

ASSEMBLEIA DA REPÚBLICA, (2006) - “Lei de Bases da Protecção Civil”, Lei n. ${ }^{\circ} 27 / 2006$, de $3 / 7$, Diário da República n. ${ }^{\circ} 126$.

CONSELHO DE MINISTROS, (2007) - "Regime jurídico da prevenção e controlo dos perigos associados a acidentes graves que envolvem substâncias perigosas", Decreto-Lei n. ${ }^{\circ} 254 / 2007$, de 12/7, Diário da República $1 .^{a}$ série $n .{ }^{\circ} 133$.

CONSELHO DE MINISTROS, (2010) - “Regime jurídico e regulamentação nacional do transporte terrestre de mercadorias perigosas, por estrada e por caminho-de-ferro", Decreto-Lei n. ${ }^{\circ}$ 41-A-2010, de 29/04, Diário da República $1 .^{\mathrm{a}}$ série $\mathrm{n} .{ }^{\circ} 83$.

LeES, Frank P., (1996), "Loss prevention in the process industries”, Butterworth Heinemann, Oxford.

MondRIL, Nuno L.F.L.C., VICÊNCIO, Henrique C., (2009) “Prevenção de riscos químicos graves pelo ordenamento do território - Regulamentação da Directiva “SEVESO II" 96/82/CE em Portugal", Autoridade Nacional de Protecção Civil.
MondRIL, Nuno L.F.L.C., (2009) - "Estimativa e representação cartográfica de impactos de acidentes químicos graves (Directiva "SEVESO II" e transporte)", Autoridade Nacional de Protecção Civil.

MondRIL, Nuno L.F.L.C., (2008) - "Guia da informação para a elaboração do plano de emergência externo (Directiva “SEVESO II”)", Cadernos Técnicos Prociv, Autoridade Nacional de Protecção Civil.

MondRIL, Nuno L.F.L.C., (2006) - "Análise quantitativa de riscos no transporte de mercadorias perigosas", Actas da Comissão Nacional do Transporte de Mercadorias Perigosas.

Mondril, Nuno L.F.L.C., (2000) - “Intervenção da protecção civil em caso de catástrofe Protecção civil e as matérias perigosas", Actas dos Seminários sobre Acidentes com Matérias Perigosas em Aveiro e Coimbra, (ed.) Escola Nacional de Bombeiros.

PARLAMENTO EUROPEU E CONSELHO, (2003) - "Controlo dos perigos associados a acidentes graves que envolvem substâncias perigosas - Directiva 'SEVESO II'”, Directiva n. ${ }^{\circ}$ 96/82/CE, de 9/12, alterada pela Directiva n. ${ }^{\circ}$ 2003/105/CE, de $16 / 12$, Jornal Oficial da União Europeia L $345 / 97$.

As ilustrações das figuras 3 e 4 foram adaptadas duma publicação do Emergency Management Institute (FEMA, EUA) por Cristina PIRES e Nuno MONDRIL. 